\title{
Impact of Job Stress on Nurses' Job Satisfaction in a Public Hospital, Cross River State, Calabar, Nigeria
}

\author{
Ella R.E. Asuquo, E.F. Paulina Ackley Akpan-Idiok, Ijabula, J.I \\ Department of Nursing Sciences, Faculty of Allied Medical Sciences, \\ College of Medicine University of Calabar, Cross River State, Nigeria
}

\begin{abstract}
:
Background: The nursing professional work environment is known to have a lot of job stress factors (stressors), that has continuously caused devastating health hazards and lack of job satisfaction among nurses (Leatt and Schneck, 2014). Understanding the impact of job stress on nurses' job satisfaction will help managements, hospital policy makers and nurse administrators develop appropriate strategies and programmes that would improve nurse's health and job satisfaction.
\end{abstract}

Purpose: The study was carried out to determine the impact of job stress on nurses' job satisfaction in the University of Calabar Teaching Hospital.

Methods: A self-developed questionnaire was administered to 115 respondents selected through simple random sampling.

Results: of the 115 respondents 107 (93.04\%) were females. 66 (57.39\%) were between ages 20-39 years. 86 (74.78\%) were married; 68 (59.13\%) respondents had diploma, while 47 (40.87\%) had BNsc, 13 (11.30\%) had Bsc in other disciplines or Post graduate qualification. 29 (25.22\%) respondents were NO11, 23 (20\%) were SNO, 19 (16.52\%). Chi square (x2) analysis revealed significant relationship between job stress and job satisfaction among nurses $(P<0.05)$. Work hazards, work load and conflicting multiple role demands emerged as stressful factors that contributed significantly to nurses' job satisfaction.

Conclusion: Work place policies that promote nurses autonomy, good nursing leadership and supervision, Implementation of WHO nurse -patient ratio of (1:4) can facilitate stress free work environment for nurses, and translate to positive health for nurses decrease lack of job satisfaction, increase nurses productivity, efficiency and quality of care.

Keywords: Nurses, Job stress, Job satisfaction.

\section{INTRODUCTION}

Nurses agitation for better working conditions have resulted in industrial disputes often culminating in strikes, work to rule, transfers to other disciplines and/or relocating to other countries for better opportunities or greener pastures in Nigeria and Cross River State in particular (Ella and Asuquo 2011). The above scenario has been strongly linked to job stress with its resultant health hazards and lack of job satisfaction among nurses (Leatt and Schneck, 2014). Understanding the impact of job stress on nurses' job satisfaction will help managements, hospital policy makers and nurse administrators develop appropriate strategies and programmes that would not only lead to better job satisfaction among nursing work force, but would also increase productivity, efficiency and quality of care.

Stress is an important psychological concept with negative consequences on the health, well-being and job performance of workers (Mojoyinola 2008). Selye (1976) stated that stress is the non specific responses of the body to the excessive demands placed on it (whether the demands are favorable or unfavorable), and that these demands produce disturbance of physiological, sociological and psychological systems. Futher more Mansoor, Fida, Nasir and Zubair (2011), stated that stress is a state that develops when the pressure or requirements of a situation on an individual are wider than he or she can handle, and if these requirements are huge and continue for a long period of time without any interval, mental, physical or behavioral problems may occur. 
Stress experienced by workers (nurses) at work place is called job stress and constitutes health risk for nurses in developing countries. Job stress describes the stress associated with the professional or work environment. The nursing professional work environment is known to have a lot of job stress factors (stressors), because the profession requires high level of skill, team work in a variety of situation; provision of 24-hour delivery of care, and input of what is often referred to as 'emotional labor' (Phillips, 2014). Emotional labors according to Nadin, (2013) have detrimental effects on the physical and psychological well being of an individual.

Stressors concern poor working conditions, interpersonal relationships at work such as conflicts with the supervisors, conflicts with colleagues, conflicts with subordinates, conflicts with other members of the health team and conflicts with management policies; role conflicts, and role ambiguity, work load, shift work, long hours of work, lack of autonomy in practice, lack of social support, poor job fit, insufficient knowledge base, unsafe work place and rapidly changing health care environment, urgency of work to be performed, dying and death patients (Mojoyinola, 2008, Olaleye,2002, Piko 2003).

Job stress responses in an individual may manifest by the presence of headache, sleep disturbances, difficulty in concentration, short temper, upset stomach, job dissatisfaction and low morale (NIOSH, 2012). Other manifestations of job stress include: illness, muscular tensions and ache, tightness in the chest, high blood pressure, heart problems, snapping and arguing with others, aggressive or hostile behavior, blaming others or administration for tension, absenteeism and high staff job turnover. The above manifestations are sometimes observed among nursing staff in a hospital setting in developing countries with resultant negative effect on their job satisfaction, their health and work behaviors and overall negative outcomes of decline in the quality of care. (Mojoyinola, 2008, NIOSH, 2012).

Job satisfaction refers to the fulfillment acquired by experiencing various job activities and rewards, and is necessary for improved job performance (Mullins, 2014). Understanding the impact of job stress on nurses job satisfaction will help managements of the hospital and policy makers to set and develop appropriate strategies and programmes that would not only lead to better job satisfaction among nursing work force, but would also increase productivity, efficiency and quality of care, and hopefully will increase patient satisfaction with care; it will also help identify the strategies and approaches that can be employed to alleviate the effects of stress on nurses, in order to increase their efficient performance in UCTH and health care delivery system in general, hence the need to undertake the study.

\section{LITERATURE REVIEW}

\subsection{Work Hazard (Physical environment) and Nurses' Job Satisfaction}

In this study hazard is synonymous with physical work environment. A work hazard carries the potential for harm. Exposure to hazard may threaten psychological and physical health (Clancy \& Mcvicar, 2014); the authors also suggests that effects of work hazard may be mediated by direct physio-chemical mechanism and that organic solvents may have a psychological effect on the nurse through their direct effects on the brain and through fear that such exposure might be harmful. Several studies have tried to determine the link between stress and job satisfaction and also identified some factors such as physical environment, role conflict and workload as stressors (Mansoor, Fida, Nasir, and Ahmed 2011; McCann, Hughes, Adair and Cardwell 2009; Lui, Ngo and Tsang 2010, Srivastava, 2008 and Ella, 1992)

Physical work environment can be defined in terms of lightening, noise, temperature, humidity, clean air, exposure to dangerous substances ( Mansoor et al 2011). A study of managers of Chinese restaurant in Honkong showed that the physical work environment is one of the important determinants of job satisfaction. Furthermore Srivastava's (2008) study of 360 technical supervisors showed that employees who perceived their physical work environment as adequate are more satisfied with their jobs. A study by Bailey, Steffen, and Grout (2014) on work hazard and job satisfaction among nurses in North Carolina also revealed low level of job satisfaction as a result of work hazards. Poor working environments are hazardous and very stressful and were believed to result in lack of job satisfaction among the nurses. 


\subsection{Role Conflict and Nurses Job Satisfaction}

Role conflict is generally defined as the simultaneous occurrence of two or more sets of pressures, such that compliance with one would make compliance with the other more difficult (Fie, Alarm, Abdullah and Ahsan, 2009 Ella 1992). Researchers have found that role conflict has a significant negative impact on job satisfaction. (Mansoor, Fida, Nasir and Zubair 2011, Ella 1992). A study on role conflict among head nurses in Birmingham also revealed that role conflict was associated with low job satisfaction and high propensity to leave (Lui, Hang-Yue, Wing-Ngar \& Tsang, 2010). Another study by McGillis (2013) on role conflict and nurses job satisfaction using a random sample of 30 Registered Nurses selected from eight (8) hospitals located in Toronto, Canada, showed that Registered Nurses in the study experienced high levels of role conflict majorly due to lack of resources and differing perceptions of how work should be carried out.

Furthermore Dewe's (2014) study with 1,800 nurses in 29 hospitals in New Zealand, identified role conflict as a major cause of job dissatisfaction among nurses. Dewe then made an important point about the finding, that nursing role is associated with multiple and conflicting demands imposed by nurse supervisors and managers, and by medical and administrative staff. This kind of a situation appears to lead to role conflict which may be most obvious when dealing with patients who are critically ill and dying, although perhaps less so when dealing with their families. However, the study of Ella, (1992) on Role conflict and job satisfaction of nurse educators in Cross River and Akwa Ibom states revealed no significant relationship between nurse educators' role conflict and their job satisfaction.

\subsection{Workload and Nurses' Job Satisfaction}

Work load could be quantitative and could lead to boredom, apathy anxiety and tension, break down, low morale and low self esteem. Nurses in Cross River State are often too overloaded with work. A situation where one nurse on night duty attends to 20-30 patients in a ward can cause frustration, anxiety low morale and conflict. This for sure is not an ideal climate in which a nurse is expected to give her best; she may thus end up stressed with resultant lack of job satisfaction. Albar Marin and Garcia-Ramirez (2012) in their study examined the effect of workload on nurses' job satisfaction among hospital nursing staff in Serville, South of Spain. They found that workload had significant effect on the level of stress and emotional exhaustion experienced by the nurses at work. Nurses that have more work load have job stress and emotional exhaustion than those who did not. Another study by Academy for Nursing Studies, (Claudio, 2014) for Training Division, Ministry of Health and Family Welfare, Government of India, India, found that the critical factors which affect the Indian nursing systems are shortage of staff and work load

Healy and McKay (2009) examined the impact of nursing work-related stressors and coping strategies on levels of job satisfaction and mood disturbance in urban and regional medical institutions in Australia. Result indicated that 'workload' was the highest perceived stressor in the nurses' working environment, which closely accords with the findings of (Tyler 2010 and Cushway 2012). Effiom, Ejue and Eworo (2007) conducted a comparative study of occupational stress among nurses and nonnurses in the University of Calabar Teaching Hospital (UCTH), Calabar, Nigeria. The subjects consisted of sixty (60) nurses and sixty (60) non-nurses selected through stratified random sampling. The study revealed that nurses of UCTH perceived heavy workload as significant stress factor intrinsically more related to their work than their non-nurses colleagues who perceived too much supervision as a significant stress factor more than nurses.

\subsection{Theoretical Framework}

This study is based within the frame work of Selye (1976), theory of General adaptation syndrome (GAS) and Herzberg's two-factor theory of Motivation. Selye (1976) physiological stress theory, popular referred to as General Adaptation syndrome theory of stress (GAS), stipulates that response to stress is non-specific and -it occurs regardless- of the nature of stress, and that disease occurs when there is failure of the resistive mechanism. Selye's physiological theory of stress is of much relevance to nurses' work stress and job satisfaction. The theory exposes that the optimal point of intervention to promote health is during the stage when a person's own compensatory processes are still functioning effectively. The role of nurses therefore is the early identification of both physiologic and psychological stressors. Nurses should be able to relate the presenting signs and symptoms of distress to the physiology they represent and identify a person's position on the continuum of function, from health and compensation to pathophysiology and disease. This will help the nurse initiate the appropriate intervention at that particular stage on the continuum of function. 


\subsubsection{Herzberg s two-factor Theory}

Within the frame work of job satisfaction, Herzberg's Theory of Motivation, a two-dimensional paradigm of factors affecting work attitudes can be regarded as theory base for job satisfaction (Okoronkwo, 2005). Factors such as supervision, interpersonal relationships, working conditions and salary are hygiene factors rather motivating factors related to overall job satisfaction. Motivating factors such as achievement, recognition, responsibility and advancement are considered to be strong determinants of job satisfaction. Motivating factors are the direct stimulating factors that give a person job satisfaction in his work and kindle positive attitude to like and love the job. The strength of these factors will affect feelings of satisfaction or no satisfaction, but not dissatisfaction. Hygiene or maintenance factors serve to prevent dissatisfaction. Herzberg's theory bears credence in this study because it exposes both the hospital management and nurses to those factors that can bring about job satisfaction and those that do not. It is expected to serve as a guide in the re-organization of nurses' duty schedule to enrich the job contents that can bring about increased job satisfaction among the nurses.

The various studies reviewed point to the fact that job stress has adverse effects on physical and mental health, personal and work behavior of nurses. It is imperative therefore that government, hospital management boards or employees of nurses be committed to the prevention or reduction of high job stress experienced by the nurses. The provision a conducive organizational climate to reduce job stress, enhance nurses' job satisfaction cannot be over emphasized, it is a task that must be given considerable attention to curb further brain drain in Cross River State. This will enhance their welfare, efficiency and quality of care given to patients. Hence the need for this study.

\subsection{Purpose of the Study}

The main aim of the study was to determine the impact of job stress on nurses' job satisfaction in the University of Calabar Teaching Hospital, Nigeria. The specific objectives were to:

- Determine the impacts of physical work environment on/and nurses' job satisfaction in University of Calabar Teaching Hospital.

- Identify the relationship between role conflict and job satisfaction among Nurses in University of Calabar Teaching Hospital.

- Assess the relationship between workload and job satisfaction among Nurses in University of Calabar Teaching Hospital.

\subsection{Hypothesis}

There is no significant relationship between job stress and job satisfaction among Nurses in University of Calabar Teaching Hospital.

\section{METHODOLOGY}

The study was a cross sectional descriptive survey. The setting was UCTH, a tertiary institution and a referral centre located in the rain forest belt in the South-South Geopolitical Zone of Nigeria. Calabar is the capital of Cross River State and is fast developing into a tourist centre. The city houses two Local Government Areas (LGAs), Calabar South and Calabar Municipality. It is a peaceful city with tourists' attraction such as Marina Resort and Tinapa, Calabar has an international airport and seaport and many other public enterprises. The people are traders, fishermen and civil servants by occupation.

The study population comprised of registered nurses of all cadre working in UCTH, totalling five hundred and sixty eight (568). Simple random sampling was used to select a sample 150 nurses from the accessible population of 362 working in the 10 wards.

\subsection{Research Setting}

The study site was University of Calabar Teaching Hospital (UCTH), Calabar, and Cross River State. It is a tertiary institution and a referral centre located in the rain forest belt in the South-South Geopolitical Zone of Nigeria. Calabar is the capital of Cross River State and is fast developing into a tourist centre. The city houses two Local Government Areas (LGAs), Calabar South and Calabar Municipality. It is a peaceful city with tourists' attraction such as Marina Resort and Tinapa, Calabar has an international airport and seaport and many other public enterprises. The people are traders, fishermen and civil servants by occupation. 


\subsection{Population}

The study population comprised of registered nurses of all cadre working in University of Calabar Teaching Hospital (UCTH). Total five hundred and sixty eight (568).

Sample

Simple random sampling was used to select a sample 150 nurses from the accessible population of 362 working in the 10 wards.

\subsection{Data Collection}

A self developed and well structured questionnaire which had two sections was used in collecting data Section A covered the characteristics of the respondents while section B measured satisfaction by 15 item scale short form of 5 item Likert's scale of Minnesota Satisfaction Questionnaire (MSQ) with 4 levels of responses. National Safety and Health, Ohio (NOISH) job stress questionnaire was used to measure job satisfaction. It consists of three sections that measured three facets of job stress in the study. The test re-test reliability coefficient was $\mathrm{r} 0.71$ to 0.85 . Face to face administration of the questionnaire was done by the researchers with the help of two research assistants who were trained on data collection. Before administering the questionnaire, the researcher introduced himself with the research assistants and explained the purpose of the study. Completed copies of questionnaire were collected same day and data collection lasted for one week. Out of the 150 questionnaires administered only 115 were found complete and fit for analysis giving a response rate of $76.6 \%$

\subsection{Data Analysis}

Data was analyzed and interpreted using simple percentages, inferential and non-inferential statistical methods. The hypothesis was tested for level of significance at 0.05 using Chi-sqaure.

\subsection{Ethical Consideration}

A written permission was obtained from The Research and Ethics Committee of UCTH to carry out the study. The respondents were adequately informed about the study and allowed to make an informed decision to partake in the study. There was no form of penalty for refusal to participate in the research and absolute confidentiality of the respondents was ensured as no name was required.

\section{Results}

Table1. Socio-demographic Data of the Respondents $n=115$

\begin{tabular}{|l|l|l|}
\hline \multicolumn{1}{|c|}{ Variables } & \multicolumn{1}{c|}{ Prequency } & \\
\hline Sex & & 6.96 \\
\hline Male & 08 & 93.04 \\
\hline Female & 107 & $\mathbf{1 0 0}$ \\
\hline Total & $\mathbf{1 1 5}$ & \\
\hline Age in years & & 23.48 \\
\hline $20-29$ & 27 & 33.91 \\
\hline $30-39$ & 39 & 21.74 \\
\hline $40-49$ & 25 & 20.87 \\
\hline 50 and above & 24 & $\mathbf{1 0 0}$ \\
\hline Total & $\mathbf{1 1 5}$ & \\
\hline Marital status: & & 21.74 \\
\hline Single & 25 & 74.78 \\
\hline Married & 86 & 0 \\
\hline Divorced/Separated & 0 & 3.48 \\
\hline Widow/widower & 4 & $\mathbf{1 0 0}$ \\
\hline Total & $\mathbf{1 1 5}$ & \\
\hline Religion: & & 96.52 \\
\hline Christianity & 111 & - \\
\hline Islam & - & 3.48 \\
\hline Traditional Religion & 4 & $\mathbf{1 0 0}$ \\
\hline Total & $\mathbf{1 1 5}$ & \\
\hline Professional qualification & & 20.87 \\
\hline RN & 24 & 8.69 \\
\hline RM & 10 & 65.22 \\
\hline RN/RM & 75 & \\
\hline & & \\
\hline
\end{tabular}


Ella R.E et al.

\begin{tabular}{|l|l|l|}
\hline \hline Others & 6 & 5.22 \\
\hline Total & $\mathbf{1 1 5}$ & $\mathbf{1 0 0}$ \\
\hline Professional Rank: & & \\
\hline ADNS & 4 & \multicolumn{1}{|c|}{3.48} \\
\hline CNO & 18 & 15.65 \\
\hline ACNO & 8 & 6.96 \\
\hline PNO & 14 & 12.17 \\
\hline SNO & 23 & 20 \\
\hline NO I & 29 & 25.22 \\
\hline NO II & 19 & 16.52 \\
\hline Total & $\mathbf{1 1 5}$ & $\mathbf{1 0 0}$ \\
\hline Educational qualification & & \\
\hline Diploma & 68 & 59.13 \\
\hline BNSC & 29 & 25.22 \\
\hline B.SC (other disciplines) & 13 & 11.30 \\
\hline Post graduate & 5 & 4.35 \\
\hline Total & $\mathbf{1 1 5}$ & $\mathbf{1 0 0}$ \\
\hline
\end{tabular}

Majority of the respondents in the study area were females 107 (93.04\%). Most respondents 66 (57.39\%) were between ages 20-39 years. Majority 86 (74.78\%) were married; $111(96.52 \%)$ of the respondents were Christians, Only 4 (3.48\%) were none Christians. Most 75 (65.22\%) had RN/RM, 24 (20.87\%) had RN. 10 (8.69\%) had RM. while 6 (5.22\%) had others. For educational qualification, most 68 (59.13\%) respondents had diploma, while 47 (40.87\%) had BNsc, Bsc in other disciplines or Post graduate qualification. 29 (25.22\%) respondents were NO11, 23 (20\%) were SNO, 19 (16.52\%).

Table2. Impact of work hazards on nurses' job satisfaction at University of Calabar Teaching Hospital

\begin{tabular}{|l|c|c|c|c|c|c|c|}
\hline \multicolumn{1}{|c|}{ Items } & \multicolumn{5}{c|}{ Responses } & Total \\
\cline { 2 - 7 } & SA & A & \% & D & SD & \% & \\
\hline Lack of adequate lighting. & 62 & 31 & 80.87 & 18 & 4 & 19.13 & 115 \\
\hline $\begin{array}{l}\text { Risk of contracting infection when carrying out certain } \\
\text { nursing procedure }\end{array}$ & 52 & 26 & 67.83 & 21 & 16 & 32.17 & 115 \\
\hline Exposure to harmful substances like carbon monoxide & 28 & 21 & 42.61 & 48 & 18 & 57.39 & 115 \\
\hline $\begin{array}{l}\text { Lack of attention given to dangerous physical conditions } \\
\text { that are hazardous to nurses }\end{array}$ & 32 & 34 & 57.39 & 36 & 13 & 42.61 & 115 \\
\hline General condition of the work environment is poor & 58 & 36 & 81.74 & 17 & 4 & 18.26 & 115 \\
\hline
\end{tabular}

Table3. Role conflict and nurses' job satisfaction in University of Calabar Teaching Hospital

\begin{tabular}{|l|c|c|c|c|l|l|l|}
\hline \multicolumn{1}{|c|}{ Items } & \multicolumn{5}{c|}{ Responses } & Total \\
\cline { 2 - 7 } & SA & A & \% & D & SD & \% & \\
\hline $\begin{array}{l}\text { I usually face role conflict associated with multiple and } \\
\text { conflicting demands imposed by nurse managers and } \\
\text { administrative staff }\end{array}$ & 44 & 28 & 62.61 & 25 & 18 & 37.39 & 115 \\
\hline Conflict among nurses in the hospital is rare & & & & & & & \\
\hline $\begin{array}{l}\text { Role conflict is common between nurses and other } \\
\text { health professional }\end{array}$ & 21 & 19 & 34.78 & 56 & 19 & 65.22 & 115 \\
\hline Role conflict makes me less proficient in my job & 21 & 16 & 32.17 & 51 & 27 & 67.83 & 115 \\
\hline $\begin{array}{l}\text { I am satisfied with the way role conflict is managed } \\
\text { among nurses }\end{array}$ & 51 & 46 & 84.35 & 11 & 7 & 15.65 & 115 \\
\hline
\end{tabular}

Table4. Workload and nurses job satisfaction in University of Calabar Teaching Hospital

\begin{tabular}{|l|c|c|c|c|c|c|c|}
\hline \multicolumn{1}{|c|}{ Items } & \multicolumn{5}{c|}{ Responses } & Total \\
\cline { 2 - 6 } & SA & $\mathbf{A}$ & $\mathbf{\%}$ & $\mathbf{D}$ & SD & \% & \\
\hline $\begin{array}{l}\text { I face too much responsibilities (Workload) which } \\
\text { can make me ineffective }\end{array}$ & 32 & 41 & 63.48 & 30 & 12 & 36.52 & 115 \\
\hline $\begin{array}{l}\text { In adequate number of nurses are available to carry } \\
\text { out a particular function }\end{array}$ & 45 & 31 & 66.1 & 24 & 15 & 33.9 & 115 \\
\hline $\begin{array}{l}\text { The rate of recruitment is not commensurate with the } \\
\text { number of staff that retire }\end{array}$ & 21 & 19 & 34.78 & 56 & 19 & 65.22 & 115 \\
\hline $\begin{array}{l}\text { Supervision of students in addition to my normal } \\
\text { schedule in the practical area is stressful }\end{array}$ & 46 & 37 & 72.17 & 16 & 16 & 27.83 & 115 \\
\hline $\begin{array}{l}\text { I am satisfied with the nurse-patient ratio in my } \\
\text { hospital }\end{array}$ & 32 & 14 & 34.78 & 48 & 21 & 52.17 & 115 \\
\hline
\end{tabular}




\subsection{Results for Research Hypothesis}

Table5. Contingency chi-square analysis of the relationship between job stress and job satisfaction among nurses in UCTH

\begin{tabular}{|c|c|c|c|c|c|c|}
\hline Variables & $\mathbf{O}$ & $\mathbf{E}$ & $\mathbf{o - e}$ & $\mathbf{( o - e )}^{\mathbf{2}} \mathbf{e}$ & $\mathbf{C a l . ~}^{\mathbf{2}}$ & Df \\
\hline SA & 34 & 23.947 & 10.053 & 4.220 & 64.116 & 1 \\
\hline A & 47 & 33.104 & 13.896 & 5.833 & & \\
\hline D & 22 & 6.504 & 15.496 & 33.919 & & \\
\hline SD & 12 & 3.547 & 8.453 & 20.144 & & \\
\hline
\end{tabular}

*Significant at 0.05; $d f=1$; Critical $X^{2}=9.49$

The result presented in Table 5 shows that the calculated $\mathrm{x}^{2}$ value of 64.116 is higher than the critical $\mathrm{x}^{2 \text { value }}$ of 9.49 at 0.05 level of significance with 1 degree of freedom. This implies that the null hypothesis is rejected. Therefore, there is a significant relationship between job stress and nurses' job satisfaction in University of Calabar teaching hospital.

\section{DISCUSSION OF FINDINGS}

\subsection{Work Hazards and Nurses' Job Satisfaction}

Responses to almost all the items in Table 2 showed that majority of the respondents agreed with the assertion that work hazards contributed negatively to nurses' job satisfaction in University of Calabar Teaching Hospital. Only the response to 'Exposure to harmful substances like carbon monoxide' had a less significant response. This finding agrees with the findings of Srivastava that employees who perceive their physical work environment as adequate are more satisfied with their jobs and vice versa. The result is also supported by the findings of Claudio, (2014), Clancy \& Mcvicar, (2012), which revealed that work hazards in health institutions which could be physical or psychological, expose nurses to potential harm. Apart from the physical conditions of the work nurses do, the psycho-social characteristics of nurses' work (for example running night shifts where the nurses are cut off from their families) and the work environment such as poor lighting are hazardous and very stressful to the nurses and constitute lack of job satisfaction among the nurses. Work hazard carries potential for harm and exposure to these harms may threaten psychological and physical health of nurses.

\subsection{Role Conflict and Nurses' Job Satisfaction}

Responses in Table 3 indicate that role conflict was not a major source of nurses' job satisfaction. This agrees with study of Ella, (1992) on Role conflict and job satisfaction of nurse educators in Cross River and Akwa Ibom states which revealed no significant relationship between nurse educators' role conflict and their job satisfaction. However nurses experienced role conflict in the area of multiple and conflicting demands imposed by nurse supervisors and managers, and by medical and administrative staff which was a source of job dissatisfaction. This is supported by Mansoor et al (2011) that multiple conflicting roles are stressors that affect job satisfaction. The researchers identified that nurse's roles are associated with multiple and conflicting demands imposed by nurse supervisors and managers, medical and administrative staff this was a major cause of job dissatisfaction among nurses. This also implies that role ambiguity is negatively associated to job satisfaction. This result is not surprising because nurses are actually confused of their roles. Most nurses in UCTH are employed from the state, where they have the free hand to perform roles such as giving injections, IV infusions, minor suturing, catheterization etc. But as they come over to UCTH they are banned from performing these duties. This kind of situation appears to lead to role conflict, which may be most obvious when dealing with patients who are critically ill and dying, although, perhaps less so when dealing with their families.

\subsection{Workload and Nurses' Job Satisfaction}

As expected the findings suggest that workload does significantly contribute to nurses' job dissatisfaction in the University of Calabar Teaching Hospital as observed in the responses in Table 4. This finding is supported by Finlayson, Dexon, Meadows and Blair (2012). The finding of Effiom, Ejue, and Eworo (2007) which revealed that nurses of University of Calabar Teaching Hospital perceived heavy workload, maintaining values and standards as significant stress factors intrinsically more related to their work than non-nurses colleagues in the same hospital who perceived too much supervision as a significant stress factor more than nurses. The result is also consistent with that of 
Albar-Marin \& Garcia-Ramirez (2012) who reported that workload had a significant effect on the level of stress and emotional exhaustion experienced by the nurses at work. Nurses that have more workload have job stress and emotional exhaustion than those who did not. They suggested adequate recruitment as one aspect to remedy workload. Obviously, many of our hospitals remain seriously understaffed with an ageing staff profile, and so recruitment efforts perhaps should be seen as medium to long term measures that will produce some significant improvement in workload stress in the near future.

\subsection{Job Stress and Nurses' Job Satisfaction}

The finding obtained from analysis and testing of the hypothesis in table 5 showed that the null hypothesis was rejected. This implies that job stress significantly relates with nurses' job satisfaction in the University of Calabar Teaching Hospital. Organizational factors such as work load; physical work environment and multiple conflicting roles are sources of stress and are negatively related with job satisfaction. Lack of satisfaction can be a source of stress, while high satisfaction can lighten the effects of stress. It means that both job stress and job satisfaction are interrelated (Mansoor et al 2011).

\section{CONCLUSION AND RECOMMENDATIONS}

Job stress has potentials to determine nurses' job satisfaction in a hospital. Some of their intrinsic or extrinsic needs may be thwarted or not be met sufficiently. The findings imply that nurses who experienced job stress in the form of workload, multiple conflicting roles and physical work environment experienced lower job satisfaction and vice versa. Nurses who are exposed to conducive work environment usually perform their job effectively and easily attain satisfaction in the performance of their job. Recommendations:

- Nursing administrators and the management of UCTH should ensure that all hazards that threaten the effective functioning of nurses in the hospital are reduced or if possible eradicated to create a conducive work environment with minimal or no hazards.

- Nursing administrators and supervisors should ensure that meaningful roles are clearly assigned based on competences and abilities to reduce the workload and to avoid role conflict.

- Some roles such as bed making, serving of bedpans should be reassigned to nurse assistants, so that nurses could concentrate more on the technical aspects of care such as wound dressing, giving of drugs, evidence based nursing etc. this will to some extent reduce nurses workload

- Nurse leaders should ensure that the WHO nurse patient ratio of (1:4) is implemented

\section{REFERENCES}

[1] Albar-Marin, M. J. \& Garcia-Ramirez. (2005). "Social Support and Emotional Exhaustion among Hospital Nursing Staff'. European Journal of Psychiatry.19 (2): 96-106.

[2] Bailey, J.T, Steffen S. M. \& Grout J W. (2014) Stress in nursing home staff.

[3] Journal of nursing education 19 (6): 15-25

[4] Claudio, T. D. (2014). Questioning workload resources. Nursing Management, 35(10), 31-34.

[5] Cushway, R. (2012). Work load and job satisfaction among nurses. American journal of nursing. $4(2), 50-55$.

[6] Effiom, D. O., Ejue, J. B. \& Eworo, G. M. (2007). A comparative study of stress among nurses and non-nurses in the University of Calabar Teaching Hospital, Calabar. West African journal of nursing. 18(2), 101-104.

[7] Ella, R. E, \& Asuquo, E, F. (2010) Organizational Climate and Nurses Job Satisfaction in Cross River Health Institutions. Global Journal of Medical Sciences. 9(2) 27-34 Indexed and Abstracted on AJOL (S.A): http://www.Ajol.info

[8] Ella, R.E (1992) Role Conflict and Nurse Educators Job Satisfaction in Cross River and Akwa Ibom States.Unpublished post graduate in partial fulfillment of the requirements for Masters in Educational Administration and Planning, University of Calabar, Calabar, pp 207

[9] Dehaas, R (2014) On line Journal of Issues in Nursing. 5(2),70-75

[10] Fie, D Y G., Alam, S S., Abdullah Z and Ahsan, N (2009). A study of job stress on job satisfaction among University staff Malaysia: Empirical study. European Journal of Social Sciences 8(1) 
[11] Healy and McKay (2013). The impact of nursing work-related stressors and coping strategies on levels of job satisfaction and mood disturbance. Australian journal of nursing.2 (2), 40-45.

[12] Herzberg F (1979) The motivation to work ( $2^{\text {nd }}$ ed) John Whiley and sons, Newyork.

[13] Leatt, P. and Schneck, R. (2010). "Differences in stress perceived by head nurses across nursing specialties in hospitals". Journal of advance nursing: 5(2), 31-46.

[14] Lui, S S., Ngo H., Tsang, A W , (2011) Interrole conflict as a predictor of job satisfaction and propensity to leave. Journal of Managerial Psychology. 16(6) 469-484

[15] Mansoor, M., Fida, S., Nasir, S., and Ahmad, Z (2011) The Impact of Job Stress on Employee Job Satisfaction. A study of Telecommunication Sector of Pakistan. Journal of Busines Studies Quarterly, 2(3) 50-56

[16] McCann, L., Hughes M., Adair, C G., and Cardwell, C (2009) Pharm World Sci 31: 118-194

[17] McGrath, A., Reid N \& Boore, J (2009). Occupational stress in nursing. International Journal of Nursing Studies 26(4). 343-358

[18] Mojoyinola, J. K. (2008). Occupational Stress Among The Student Nurses of University College Hospital (U.C.H), Ibadan: It's Effects on Their Mental

[19] Mullins, S. (2014) Job satisfaction among polish retail sales people. Journal of Business Research. 56(971-978

[20] Nadin, S.A. (2013) The impact of job stress on nurses job satisfaction. Journal of Occupational Health 2(3) 50-56

[21] National Institute for Occupational Safety and Health. (2008). "Stress at Work: Job Stress and Health." Retrieved October, 2nd, 2015, from http://www.cdc/ gov/noish/jobstress.html.

[22] Olaleye, B. A. (2002). Psycho-Social Effects of Job Stress and Burn-out Syndrome among Nurses in State- Owned Hospitals in Oyo State. M.S.W. Project, (Unpublished) University of Ibadan, Nigeria.

[23] Okoronkwo,I (2005) Nursing Service Administration and Managent. Theory and Practice. Institute for Developmental Studies, Enugu Campus, Nigeria

[24] Philips, J (2014) Emotional Labor and Probiation. Journal of Social Sciences and Medicine, 2(3) 102-109

[25] Piko, B. F., (2003) psychosocial work environment and psychosomatic health of nurses in Hungary. Work and Stress, 17(1): 93-100

[26] Selye, H. (1796). The Stress of Life. New York: McGraw-Hill

[27] Srivastava, A K (2008) Effect of perceived work environment on Employees' job behavior and Organizational effectiveness. Journal of Indian Academy of Applied Psychology, 34(1) 47-55

[28] Tyler, B. (2010). Job stress and job satisfaction in nursing. British journal of nursing. 2(3), 3034.

\section{AUTHORS' BIOGRAPHY}

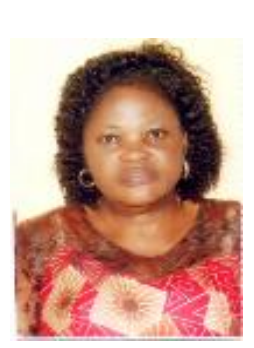

Regina E. Ella, is a Nigerian Registered Nurse/Midwife with B. Sc Nursing; M.Ed and $\mathrm{Ph}$. D with specialization in Educational Administration and Planning. She currently works as a senior lecturer with the University of Calabar. She has worked with the Cross River State Government as Secretary and Coordinator of the State Agency for Aids Control; as Palliative Care Advisor with CEDPA on HIV/AIDS Positive Living Project; Consultant trainer on HIV/AIDS Palliative Care with MSH. She is a Master trainer of trainers with CEDPA on HIV/AIDS Palliative Care. Her areas of interest are Nursing Education and HIV/AIDS. Dr Ella is a Fellow of The West Afriacn College of Nursing (WACN). A member of International Council for Nurses, member of the Honor society of Nursing (STTI) LAMDA Nigerian Chapter, and Member of American Public Health Association (APHA)

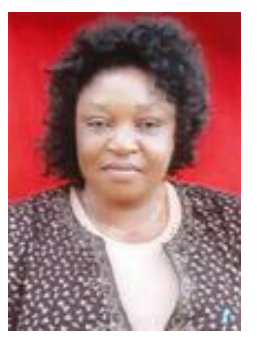

Asuquo, Ekaete Francis RN, BSc, MNSc, PhD Nursing is working in the Department of Nursing Sciences, University of Calabar, Nigeria her Area of Specialisation is the fields of Medical Surgical Nursing with special interest in maternal and Child health. For the past years I have been involved in studying the challenges faced by HIV patients, mothers and children (Clinical Research on HIV and AIDS) and the role of nurses in providing health care services to these categories of people especially in the Low and Medium Income countries such as 
Ella R.E et al.

Nigeria in West Africa. Other research interests include Health Services Research, health policies and power inequities, Community and Health system mobilization through Participatory Action Research, Critical qualitative and quantitative methodologies, Nurses' capacity building, Maternal, Newborn and Child Health, Nursing education and professional practice.

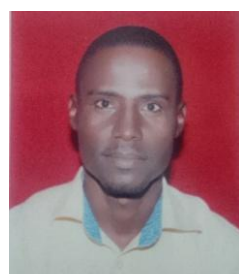

Ijaida Joseph Ijabula, is from Adamawa State, Nigeria. He studied in the College of $\mathrm{N}$ ursing Yola in 2004 and Registered as a nurse that same year. He is a Registered Nurse Tutor (2011) and a graduate of nursing science from University of Calabar 2015. He is someone who is mature, candid and who has integrity. $\mathrm{He}$ works to improve himself and his skills which is part of maturing and becoming better at what he can do."

Mrs. Paulina Ackley Akpan-Idiok, is a registered midwife, nurse, public health nurse, nurse educator, and holds a BSc. degree in Nursing(Hons); currently Lecturer II at the University of Calabar, Nigeria. Paulina also holds a MSc degree in Medical Surgical Nursing from the University of Nigeria, Nsukka. She is a PhD student in the same University who is currently researching into: "Supportive Interventions for Advanced Family Cancer Caregivers in Nigeria. 